\title{
Role of Micro Finance in Empowering Indian Women
}

\author{
Dr. Mohini Agarwal
}

\begin{abstract}
Empowerment provides a greater access to knowledge and resources, more independence in decision making, considerable ability to plan lives, more control over the circumstances which influence lives, and freedom from customs, beliefs and practices. Thus, women empowerment is a process in which women challenge the existing norms and culture, to effectively promote their well being.

The more comprehensive concept of gender empowerment refers to people of any gender, stressing the distinction between biological sex and gender as a role. It thereby also refers to other marginalized genders in a particular political or social context.

In this paper we will discuss the role of microfinance and importance of Self help groups in enabling women to stand on their feet and how it is significant in improving women's condition in Indian context.
\end{abstract}

Keywords - Women Empowerment, SelfHelp Groups, Microfinance, Gender etc

\section{INTRODUCTION}

$\mathrm{W}$ OMEN empowerment, referring to the empowerment of women in our present society, has become a significant topic of discussion in regards to development and economics. It can also point to approaches regarding other trivialized genders in a particular political or social contexts.

There are still uneducated and poor town ladies fiscally reliant on their relatives, despite the fact that they are persevering and have their own particular capacities to be monetarily self-subordinate. Still, they won't land any great position and no money-related backing to begin their own particular family unit businesses and additionally fare well.

Entire nations, businesses, communities, and groups can benefit from the implementation of programs and policies that adopt the notion of women empowerment. ${ }^{[3]}$ Empowerment is one of the main procedural concerns when addressing human rights and development. The Human Development and Capabilities Approach, theMillennium Development Goals, and other credible approaches/goals point to empowerment and participation as a necessary step if a country is to overcome the obstacles associated with poverty and development.

Dr. Mohini Agrawal is an Asso Professor in the Department of Economics MahilaMahavidyalaya, P.G.College, Kanpur (U.P.), India.

\section{ROLE OF MiCROFINANCE}

Micro Finance is emerging as a powerful instrument for poverty alleviation in the new economy. In India, micro finance scene is dominated by Self Help Groups (SHGs) Bank Linkage Programme, aimed at providing a cost effective mechanism for providing financial services to the "unreached poor". Based on the philosophy of peer pressure and group savings as collateral substitute, the SHG programme has been successful in not only in meeting peculiar needs of the rural poor, but also in strengthening collective self-help capacities of the poor at the local level, leading to their empowerment.

Micro Finance for the poor and women has received extensive recognition as a strategy for poverty reduction and for economic empowerment. Increasingly in the last five years , there is questioning of whether micro credit is most effective approach to economic empowerment of poorest and, among them, women in particular. Development practitioners in India and developing countries often argue that the exaggerated focus on micro finance as a solution for the poor has led to neglect by the state and public institutions in addressing employment and livelihood needs of the poor.

Credit for empowerment is about organizing people, particularly around credit and building capacities to manage money. The focus is on getting the poor to mobilize their own funds, building their capacities and empowering them to leverage external credit. Perception women is that learning to manage money and rotate funds builds women's capacities and confidence to intervene in local governance beyond the limited goals of ensuring access to credit. Further, it combines the goals of financial sustainability with that of creating community owned institutions.

Before 1990's, credit schemes for rural women were almost negligible. The concept of women's credit was born on the insistence by women oriented studies that highlighted the discrimination and struggle of women in having the access of credit. However, there is a perceptible gap in financing genuine credit needs of the poor especially women in the rural sector.

There are certain misconception about the poor people that they need loan at subsidized rate of interest on soft terms, they lack education, skill, capacity to save, credit worthiness and therefore are not bankable. Nevertheless, the experience of several SHGs reveal that rural poor are actually efficient managers of credit and finance. Availability of timely and adequate credit is essential for them to undertake any economic activity rather than credit subsidy. 
The Government measures have attempted to help the poor by implementing different poverty alleviation programmes but with little success. Since most of them are target based involving lengthy procedures for loan disbursement, high transaction costs, and lack of supervision and monitoring. Since the credit requirements of the rural poor cannot be adopted on project lending app roach as it is in the case of organized sector, there emerged the need for an informal credit supply through SHGs. The rural poor with the assistance from NGOs have demonstrated their potential for self help to secure economic and financial strength. Various case studies show that there is a positive correlation between credit availability and women's empowerment.

Surveys have shown that many elements contribute to make it more Difficult for women empowerment through micro businesses. These elements are:

- Lack of knowledge of the market and potential profitability, thus

Making the choice of business difficult.

- Inadequate book-keeping.

- Employment of too many relatives which increases social pressure to share benefits.

- $\quad$ Setting prices arbitrarily.

- Lack of capital.

- High interest rates.

- Inventory and inflation accounting is never undertaken.

- Credit policies that can gradually ruin their business (many customers cannot pay cash; on the other hand, suppliers are very harsh towards women).

Other shortcomings includes,

1. Burden of meeting: Time consuming meetings, in particular in programmes based on group lending, and time consuming income generating activities without reduction of traditional responsibilities increase women's work and time burden.

2. New Pressures: By using social capital, in-group lending/group collateral programmes, additional stresses and pressures are introduced, which might increase vulnerability and reflect disempowerment.

3. Reinforcement of traditional gender roles : lack of economic empowerment: Micro finance assists women to perform traditional roles better and women thus remain trapped in low productivity sectors, not moving from the group of survival enterprises to micro-enterprises. There are evidence of men withdrawing their contributions to certain types of household expenditures.

\section{CONCLUSION}

A conclusion that emerges from this account is that micro finance can contribute to solving the problems of inadequate housing and urban services as an integral part of poverty alleviation programmes. The challenge lies in finding the level of flexibility in the credit instrument that could make it match the multiple credit requirements of the low income borrower without imposing unbearably high cost of monitoring its end use upon the lenders. A promising solution is to provide multipurpose lone or composite credit for income generation, housing improvement and consumption support. Consumption loan is found to be especially important during the gestation period between commencing a new economic activity and deriving positive income. Careful research on demand for financing and savings behavior of the potential borrowers and their participation in determing the mix of multi-purpose loans are essential in making the concept work.

\section{REFERENCES}

[1] Chen .1997. Cited in Linda Mayoux, Gender and empowerment concepts, September 2005, available at http://www.genfinance.info/Documents/GenderConcepts.pdf.

[2] Cheston, and Lisa Kuhn.2002. Empowering women through microfinance, Publication sponsored by UNIFEM, available at www.microcreditsummit .org/papers/+ 5cheston_kuhn.pdf

[3] Ghate ,Prabhu. 2008. Micro finance in India - A state of the sector report (2007). New Delhi: Sage publications.

[4] Johnson, Susan .2004. The impact of microfinance institutions in local financial markets: a case study from Kenya, Journal of International Development, https://doi.org/10.1002/jid.1088

[5] Kabeer, Naila.2005. Is microfinance a magic bullet for women empowerment? Analysis of South Asia, Economic and Political Weekly, 40(44), 4709-4718. 